\title{
Perbandingan Pembelajaran PPKn Pada Implementasi KTSP dan Kurikulum 2013 Di Sekolah Menengah Pertama (SMP)
}

\author{
Bhakti Prima Findiga Hermuttaqien $^{\text {a, }{ }^{*} \text {, Haula Ria Sata }}{ }^{\text {b, },}$, Ludovikus Bomans Wadu ${ }^{\text {c, } 3}$ \\ ${ }^{a}$ Universitas Negeri Makassar, Indonesia \\ b,c Universitas Kanjuruhan Malang, Indonesia \\ ${ }^{1}$ bhakti@unm.ac.id *; ${ }^{2}$ haularia26@gmail.com ${ }^{3}$ ludovikusbomanwadu@unikama.ac.id \\ *korespondensi penulis
}

\section{Informasi artikel}

Received :

November 26, 2018

Revised :

Desember 13,2018.

Publish :

January 31, 2019.

Kata kunci:

Pembelajaran PPKn

KTSP

Kurikulum 2013

\begin{abstract}
ABSTRAK
Penelitian ini bertujuan untuk melihat perbandingan pembelajaran PPKn menggunakan KTSP dan Kurikulum 2013di SMP. Metode dalam penelitian ini yaitu deskriptif kuantitatif. Pemilihan sampel pada penelitian menggunakan teknik purposive (nonprobabilty) sampling. Frekuensi jawaban responden ketegori guru pada implementasi KTSP kategori pembukaan sebesar 54.5\%, kategori inti sebesar $63.6 \%$, kategori penutup sebesar 63.6\% sedangkan penilaian kurikulum 2013 frekuensi jawaban responden kategori pembukaan sebesar 72.7\%, kategori inti sebesar 63.6\%, kategori penutup sebesar $81.8 \%$. Disimpulkan dari penelitian menunjukkan terdapat perbandingan pembelajaran PPKn dengan implementasi KTSP dan Kurikulum 2013 di SMP Se Kecamatan Turen. Hal ini dibuktikan dengan nilai $\mathrm{t}_{\text {hitung }} 2.930$ dan $\mathrm{t}_{\text {tabel }} 2.201$ yang artinya nilai $t_{\text {hitung }}$ lebih besar dari $t_{\text {tabel }}$ dengan nilai sig 2 tailled $0,008<0,05$.
\end{abstract}

\begin{abstract}
Comparison of PPKn Learning in KTSP And Curriculum 2013 Implementation in Junior High Schools. This study aims to look at the comparison of PPKn learning using KTSP and Curriculum 2013. The method in this study is descriptive quantitative. The sample is chosen by using purposive (nonprobability) sampling. It results that the answer frequency of teachers on KTSP, i.e. $54.5 \%$ for opening category, $63.6 \%$ for main category, and 63.6\% for closing category; while on 2013 Curriculum, i.e. $72.7 \%$ for opening category, $63.6 \%$ for main category, and $81.8 \%$ for closing category. The study concludes that there is comparison of learning PPKN through KTSP and 2013 Curriculum in Junior High Schools in Turen. It is proven by $t_{\text {value }} 2.930$ and $t_{\text {table }} 2.201$ which mean $t_{\text {value }}$ is bigger than $t_{\text {table }}$ by the difference sig 2 tailled $0.008<0.05$.
\end{abstract}

Copyright () 2019 (Bhakti P. F. Hermuttaqien, Haula Ria Sata, Ludovikus B.

Wadu). All Right eserved
Keywords:

KTSP

Curriculum 2013

How to Cite: Hermuttaqien, B., Sata, H., \& Wadu, L. (2019). Perbandingan Pembelajaran PPKn pada Implementasi KTSP dan Kurikulum 2013 di Sekolah Menengah Pertama (SMP). Jurnal Inspirasi Pendidikan, 9(1), 39-44.

This work is licensed under a Creative Commons Attribution-ShareAlike 4.0 International License. Allows readers to read, download, copy, distribute, print, search, or link to the full texts of its articles and allow readers to use them for any other lawful purpose. The journal hold the copyright. 
Jurnal Inspirasi Pendidikan, VOL.9, NO.1, Edisi Januari 2019 Perbandingan Pembelajaran PPKn Pada Implementasi KTSP dan Kurikulum 2013 di SMP Bhakti Prima Findiga Hermuttaqien ${ }^{\text {a, }}{ }^{*}$, Haula Ria Sata ${ }^{\text {b, } 2}$, Ludovikus Bomans Wadu ${ }^{\text {c, } 3}$

\section{Pendahuluan}

Pendidikan merupakan pondasi untuk membangun generasi berikutnya dan sebagai perlindungan lingkungan yang dapat membentuk norma-norma dan dapat mengasilkan nilai-nilai dan perilaku yang baik (Post \& Meng, 2018). Selain itu pendidikan juga memiliki aspek terpenting dalam mencerdaskan bangsa, peningkatan dan perbaikan mutu pendidikan (Rosmani, 2017). Pendidikan di Indonesia diarahkan kedalam pendidikan nasional yang mengembangkan kemampuan dan membentuk watak serta peradaban bangsa yang bermartabat dan mencerdaskan serta menjadi warga negara yang bertanggung jawab sesuai Undang-undang No. 20 Tahun 2003 tentang sistem pendidikan nasional. Maka dari itu pendidikan merupakan bagian terpenting bagi manusia untuk mendapatkan kualitas pembelajaran yang baik.

Orientasi pendidikan di Indonesia adalah untuk meningkatkan kualitas pembelajaran (Mulyasa, 2016). Dalam mewujudkan kualitas pembelajaran terhadap siswa guru harus kreatif dan inovatif dalam proses pembelajaran berlangsung. Jika kualitas pembelajaran ditingkatkan maka akan mempengaruhi tingkat prestasi dan motivasi belajar. Selain itu pembelajaran yang berkualitas dapat mengembangkan kemampuan dan watak peserta didik (Hakim D. , 2017). Dengan demikian guru termasuk bagian komponen dalam sistem pendidikan untuk menjadikan generasi bangsa menjadi manusia yang berkualitas sesuai dengan tujuan pendidikan nasional.

Indonesia sudah mengalami beberapa kali perubahan kurikulum. Menurut Suparlan (2012) kurikulum pertama Indonesia adalah rencana pelajaran 1947. Setelah mengalami beberapa perubahan dalam kurikulum, salah satu contohnya ialah Kurikulum Tingkat Satuan Pendidikan (KTSP) 2006. KTSP merupakan bagian yang tidak dapat dipisahkan dari Standart Isi (SI), pada dasarnya Standart Isi (SI) dan Standart Kompetensi Lulusan (SKL) dijadikan acuan untuk pelaksanaan KTSP (Uce, 2016).

Salah satu bentuk pengembangan kurikulum yang dilakukan oleh pemerintah dari KTSP ialah Kurikulum 2013, dimana pengembangan kurikulum 2013 adalah untuk menghasilkan insan Indonesia yang produktif, kreatif, inovatif, dan afektif melalui penguatan sikap, keterampilan dan pengetahuan yang terintegrasi (Rosmani, 2017). Proses pembelajaran Kurikulum 2013 yaitu terfokus pada eksplorasi,elaborasi, dan konfirmasi dilengkapi dengan mengamati, menanyakan, mengolah, menyajikan, menyimpulkan dan mencipta saat proses pembelajaran tidak hanya terjadi di ruang kelas, tetapi juga di lingkungan sekolah dan masyarakat (Hakim L. , 2017). Proses belajar mengajar di Kurikulum 2013 tidak hanya mendengarkan penjelasan materi dari guru melainkan bisa mengamati dengan menggunkan media seperti: vidio, alat peraga dan gambar. Jadi peserta didik diharuskan untuk berperan aktif dalam proses pembelajaran.

Pembelajaran Pendidikan Pancasila dan Kewarganegaraan (PPKn) merupakan kegiatan pembelajaran yang membentuk watak peserta didik agar menjadi warga negara yang baik dan bertanggung jawab dalam kehidupan sehari-hari. Pembelajaran PPKn memeliki peran penting dalam pengembangan kurikulum. Salah satunya contohnya dalam pengembangan kurikulum 2013 materi PPKn disajikan tidak berdasarkan pada pengelompokan menurut empat pilar kebangsaan tetapi berdasarkan keterpaduan empat pilar pembentukan karekter bangsa. Materi disajikan berdasarkan kebutuhan peserta didik agar menjadi warga negara yang bertanggungjawab (taat norma, asas dan aturan) (Hakim L. , 2017).

Berdasarkan asumsi-asumsi di atas, penerapan Kurikulum 2013 pada tahun pelajaran 20182019 sudah diterapkan disekolah-sekolah termasuk Sekolah Menengah Atas (SMP). Fenomena yang terjadi dari hasil wawancara sebagian guru yang usianya masih muda sudah mengajak siswa untuk berperan aktif dalam pembelajaran, menggunakan teknik untuk mengajar, tetapi respon peserta didik masih biasa-biasa saja, begitupun dengan pendapat guru yang senior mengatakan bahwa respon peserta didik saat pembelajaran juga biasa saja, ada yang mengantuk, berbicara dengan teman. Dari permasalahan di atas masih ada beberapa permasalahan di SMP Se Kecamatan Turen yaitu implementasi pembelajaran PPKn dalam KTSP dan Kurikulum 2013. Sebagai contoh, kurikulum 2013 untuk menghasilkan generasi Indonesia yang produktif, kreatif, inovatif, afektif, melalui penguatan sikap, ketrampilan, dan pengetahuan (Mulyasa, 2016).

Pembelajaran merupakan suatu proses yang dilakukan seseorang secara sengaja bahwa lingkungan juga mempengaruhi dalam kondisi khusus (Badriyah, 2015). PPKn merupakan pendidikan yang memberikan ilmu sebagai warga negara yang berpancasila (Satriya, 2015). Selain itu PPKn juga mempersiapkan warga negara yang memiliki sikap, pengetahuan politik dan partisipasi politik agar 
Jurnal Inspirasi Pendidikan, VOL.9, NO.1, Edisi Januari 2019 Perbandingan Pembelajaran PPKn Pada Implementasi KTSP dan Kurikulum 2013 di SMP Bhakti Prima Findiga Hermuttaqien ${ }^{\text {a, }}{ }^{*}$, Haula Ria Sata ${ }^{\text {, } 2}$, Ludovikus Bomans Wadu ${ }^{\text {c, } 3}$

Hal: $39-44$

menjadi warga negara yang bijak (Taniredja, 2009). Oleh karena itu pembelajaran PKn dapat diartikan sebagai pembelajaran yang dapat menerapkan pancasila di lingkungan, berbangsa dan bernegara dan menjadikan warga negara yang baik.

KTSP merupakan jantung pendidikan bagi Indonesia serta memberikan perhatian terhadap pendidikan budaya dan karakter bangsa dibandingkan kurikulum masa sebelumnya (Hakim D. , 2017). Komponen Kurikulum Tingkat Satuan Pendidikan Komponen Kurikulum Tingkat Satuan Pendidikan dapat juga diartikan sebagai sistem (Poniyem, 2016). Komponen KTSP terdiri dari tujuan pendidikan, struktur program dan muatan kurikulum, kalender pendidikan, silabus dan rencana pelaksanaan pembelajaran (Sanjaya, 2008). Maka dengan KTSP diharapkan dapat menyempurnakan kurikulum berikutnya.

KTSP berperan aktif terhadap kepala sekolah dan guru. Dalam implementasi KTSP ini Kepala Sekolah menyusun tentang rencana tahunan, menyusun jadwal pelaksanaan kegiatan , memimpin rapat dan membuat notula rapat dan menyusun laporan (Dewi \& Setyo, 2014). Selain itu kepala sekolah juga harus mengembangkan kurikulum setiap mata pelajaran, program pembelajaran dilakukan dalam kelas, laboratorium, lapangan, maupun tempat lain, meningkatkan kemampuan guru melalui workshop ataupun pelatihan lain, penelitian tindakan, mengembangkan minat dan bakat peserta didik, meningkatkan pendayagunaan perpustakaan, dan membuat berbagai program sekolah yang dapat meningkatkan kualitas sekolah (Sagala, 2013). Sedangkan peran guru dalam implementasi KTSP ialah pembagian tugas mengajar Menyusun rencana pelaksanaan program pembelajaran, menyusun jadwal kegiatan, pengisian daftar penilaian, pengisian buku laporan pribadi siswa.

Kurikulum 2013 merupakan lanjutan dan penyempurnaan dari Kurikulum Berbasis Kompetensi (KBK) dan Kurikulum Tingkat Satuan Pendidikan (KTSP) yang mengutamakan nilai pengetahuan, sikap dan ketrampilan peserta didik (Albantani, 2015). Komponen kurikulum 2013 meliputi tujuan pendidikan, materi, strategi pembelajaran yang menyenangkan, organisasi kurikulum, evaluasi. Implementasi kurikulum 2013 merupakan wujud kurikulum dalam pembelajaran dan pembentukan kompetensi serta karakter pada diri peserta didik (Mulyasa, 2016). Kurikulum ini merupakan langkah yang dilakukan pemerintah untuk memperbaiki kualitas pendidikan.

Peran kepala sekolah agar kurikulum 2013 dapat berjalan dengan baik ialah melakukan pembinaan mental terhadap guru, pembinaan moral kepada guru dan peserta didik, pembinaan fisik,pembinaan artisik. Selain kepala sekolah guru juga berperan dalam implementasi kurikulum 2013 yaitu menyusun RPP yang didalamnya memuat kegiatan pendahuluan, inti dan penutup. Dalam penyusunan RPP harus melibatkan peserta didik agar lebih aktif dalam pembelajaran. Sehingga dalam kurikulum 2013 pembuatan RPP mengembangkan dari silabus yang sudah dibuat pemerintah dan menyesuaikan kondisi sekolah dan peserta didik.

\section{Metode}

Jenis penelitian ini adalah penelitian deskriptif kuantitatif. Analisis data menggunakan uji normalitas data dilakukan untuk mengetahui data yang dihasilkan terdistribusi normat atau tidak,uji normalitas dengan taraf signifikan $(\alpha)=0,05$, jika nilai signifikansi hasil perhitungan nilai 2 tailled $\mathrm{p}>$ a data adalah normal, dan jika nilai 2 tailled $\mathrm{p}<$ a berarti data tidak normal. Uji normalitas dilakukan dengan SPSS 24. Perbandingan KTSP dan Kurikulum 2013 pada pembelajaran PPKn dengan melakukan uji perbandingan. Data yang terdistribusi normal menggunakan uji-t (two independent sample t-test). Dengan nilai signifikan yang diperolah $t_{\text {hitung }}$ lebih besar $t_{\text {tabel }}$ maka data tersebut terdapat perbandingan. Pengolahan data angket dilakukan dengan cara kuantitatif.

\section{Hasil dan pembahasan}

Perbandingan pembelajarn PPKn pada implementasi KTSP dan Kurikulum 2013 memiliki 2 responden yaitu kepala sekolah dan guru PPKn. Data hasil perbandingan pembelajaran PPKn pada kategori kepala sekolah terdapat perbedaan pada implementasi KTSP dan Kurikulum 2013 di SMP kategori kepala sekolah, hal ini dibuktikan dengan nilai $t_{\text {hitung }}$ lebih besar dari $t_{\text {tabel }}$ dengan nilai sig 2 tailled yaitu sebesar $(a)<0,05$. Perbedaan pembelajaran PPKn dengan implementasi KTSP dan Kurikulum 2013 kategori guru terdapat perbedaan pembelajaran PPKn pada implementasi KTSP dan Kurikulum 2013 di SMP se Kecamatan Turen hal ini dibuktikan dengan nilai $\mathrm{t}_{\text {hitung }}$ lebih besar dari $\mathrm{t}_{\text {tabel }}$ dengan nilai sig 2 tailled yaitu sebesar $(\mathrm{a})<0,05$. 
Jurnal Inspirasi Pendidikan, VOL.9, NO.1, Edisi Januari 2019 Perbandingan Pembelajaran PPKn Pada Implementasi KTSP dan Kurikulum 2013 di SMP Bhakti Prima Findiga Hermuttaqien ${ }^{\text {a, }}{ }^{*}$, Haula Ria Sata ${ }^{\text {, } 2}$, Ludovikus Bomans Wadu ${ }^{\text {c, } 3}$

Hal: $39-44$

Hasil menunjukkan bahwa nilai uji t yang diperoleh dari 5 SMP Se Kecamatan Turen menunjukkan bahwa secara statistik ada perbedaan yang signifikan antara pembelajaran PPKn dengan implementasi KTSP dan Kurikulum 2013, dimana nilai $t_{\text {hitung }}$ lebih besar dar $t_{\text {tabel. }}$ Hal ini membuktikan bahwa proses pembelajaran PPKn dengan implementasi Kurikulum 2013 lebih efektif.

Penilaian pembelajaran PPKn dengan menggunakan KTSP memperoleh nilai sebesar $63.6 \%$. Sedangkan penilaian dalam kurikulum 2013 sebesar 72.7\%. SMP sudah menerapakan kurikulum 2013 di kelas VII dan VIII sedangkan untuk kelas IX menggunakan KTSP tetapi untuk tahun pelajaran yang akan datang semua kelas menggunakan kurikulum 2013. Dengan kurikulum 2013 peserta didik akan lebih aktif dan efektif dalam proses pembelajaran PPKn.

Hasil penelitian yang sudah dilakukan sesuai dengan penelitian (Rosmani, 2017) melaporkan hasil penelitiannya menunjukkan bahwa penerapan KTSP dan kurikulum 2013 terhadap perbandingan nilai kimia ketiga sekolah favorit di Banda Aceh baik dalam menyelesaikan tugas dan kegiatan dalam pembelajaran yaitu SMA 10 sebesar 95\%, SMA 3 sebesar 75\% dan LAB School sebesar 100\%. Penelitian yang sama juga di lakukan oleh (Mukroni, 2017) pelaksanaan pembelajaran dan penilaian pembelajaran Guru Ekonomi SMAN 2 Sentajo Raya terhadap kepuasan siswa hanya sebesar 28,4\%.

Perbedaan paling mendasar pada pembelajaran PPKn dengan implementasi KTSP dan Kurikulum 2013 yaitu terletak pada penilaian. Penilaian yang mendukung kompetensi pengetahuan, sikap dan ketrampilan pada KTSP hanya ada pada mata pelajaran tertentu, tetapi pada Kurikulum 2013 tiap mata pelajaran mendukung semua kompetensi (pengetahuan,sikap dan ketrampilan) (Mulyasa, 2016). Kompetensi inti dan kompetensi dasar harus sesuai dengan kemampuan peserta didik selain itu materi pembelajaran harus sesuai dengan silabus (Marwiyah, 2018). Sehingga Kurikulum 2013 yang berbasis karakter ini diharapkan dapat memberikan solusi dalam bidang pendidikan untuk mempersiapkan peserta didik agar berhasil (Hidayati, 2015).

Berdasarkan penjelasan diatas, persentase secara keseluruhan menunjukkan bahwa Kurikulum 2013 memiliki nilai prosentase paling tinggi. Hal ini membuktikan bahwa pembelajaran PPKn dengan implementasi kurikulum 2013 sudah efektif. Banyak yang menduga bahwa kurikulum 2013 lebih susah dari KTSP. Pada kenyataannya kurikulum 2013 lebih efektif untuk diterapkan dalam pembelajaran PPKn dilihat dari proses pembelajaran, peserta didik lebih aktif dalam melaksanakan tugas dan kegiatan yang diberikan guru.

Dilihat dari prosentase jawaban 5 SMP yang menjawab kurikulum 2013 lebih efektif dapat dilihat di tabel 1 kategori kepala sekolah sebesar nilai $\mathrm{t}_{\text {hitung }} 3.618 \mathrm{t}_{\text {tabel }} 2.201$ dengan nilai sig 2 tailled yaitu sebesar $0,007<0,05$. Pada tabel 2 kategori guru sebesar nilai $t_{\text {hitung }} 2.930 t_{\text {tabel }} 2.201$ dengan nilai sig 2 tailled yaitu $0,008<0,05$. Dapat disimpulkan bahwa peserta didik dengan kurikulum 2013 lebih aktif dan efektif dalam pembelajaran PPKn . Sesuai dengan penelitian (Albantani, 2015), melaporkan bahwa kelebihan kurikulum 2013 merupakan peserta didik lebih kreatif dan inovatif, pendidikan budi pekerti dan karakter diintegrasikan kesemua program studi dan mata pelajaran.

Kelebihan dalam kurikulum 2013 penyusunan silabus Pengembangan dari yang sudah disiapkan dan penyusunan rencana pelaksanaan pembelajaran kecil, untuk pengembangan dari yang ada pada buku teks. Selain itu dalam proses pembelajaran hampir mutlak dikuasi oleh guru karena dalam kurikulum 2013 peserta didik lebih dilibatkan dalam pembelajaran dan tiap mata pelajaran mendukung semua kompetensi (sikap, ketrampilan, pengetahuan). Jika dalam KTSP TIK dijadikan sebagai mata pelajaran sendiri tetapi dalm Kurikulum 2013 TIK merupakan sarana pembelajaran yang mendukung peserta didik yang digunakan sebagai media pembelajaran mata pelajaran lain. Dalam standar penilaian kurikulum 2013 menggunakan penilaian otentik dan menyeluruh yaitu mengukur semua kompetensi sikap, ketrampilan, dan pengetahuan berdasarkan proses dan hasil peserta didik.

Hal ini didukung oleh penelitian Lukmanul Hakim mengatakan strategi pembelajaran dalam Pendidikan Pancasila dan Kewarganegaraan materi disajikan tidak berdasarkan pada pengelompokan menurut empat pilar kebangsaan tetapi berdasarkan keterpaduan empat pilar pembentukan karekter bangsa. Materi disajikan berdasarkan kebutuhan peserta didik agar menjadi warga negara yang bertanggungjawab (taat norma, asas dan aturan). Adanya kompetensi yang dituntut dari peserta didik untuk melakukan tindakan nyata sebagai warga negara yang baik. Pancasila dan kewarganegaraan bukan hanya pengetahuan, tetapi ditunjukkan melalui tindakan nyata dan sikap keseharian.

Pada proses pembelajaran PPKn dengan implementasi kurikulum 2013 peserta didik dilibatkan secara aktif. Guru menerapkan kegiatan pembukaan atau awal pembelajaran kepada peserta 
Jurnal Inspirasi Pendidikan, VOL.9, NO.1, Edisi Januari 2019 Perbandingan Pembelajaran PPKn Pada Implementasi KTSP dan Kurikulum 2013 di SMP Bhakti Prima Findiga Hermuttaqien ${ }^{\text {a, }}{ }^{*}$, Haula Ria Sata ${ }^{\text {b, } 2}$, Ludovikus Bomans Wadu ${ }^{\text {c, } 3}$ Hal: $39-44$

didik cukup baik hal ini dibuktikan dengan prosentase jawaban responden $72.7 \%$. Sedangkan kegiatan inti guru menerapkan dengan cukup baik hal ini dibuktikan dengan prosentase jawaban responden 63.6\%. Sedangkan di akhir pembelajaran guru menerapkan dengan cukup baik hal ini dibuktikan dengan prosentase jawaban responden $81.8 \%$. Untuk penilaian kepada peserta didik guru menerapkan dengan cukup baik hal ini dibuktikan dengan prosentase jawaban responden $72.7 \%$. Selain itu untuk pengembangan kegiatan rencana pembelajaran guru menerapkan dengan baik hal ini dibuktikan dengan prosentase jawaban responden $45.5 \%$.

\section{Simpulan}

Pembelajaran PPKn dengan menggunakan KTSP kurang efektif. Hal ini dibuktikan dengan hasil jawaban responden kategori guru sebesar 63.6\%. Sedangkan pembelajaran PPKn dengan menggunakan Kurikulum 2013 lebih efektif. Hal ini dibuktikan dengan hasil jawaban responden kategori guru sebesar $72.7 \%$. Maka terdapat perbandingan pembelajaran PPKn dengan implementasi KTSP dan Kurikulum 2013 di SMP Se Kecamatan Turen. Hal ini dibuktikan dengan hasil jawaban responden KTSP sebesar 63.6\% dan hasil jawaban responden Kurikulum 2013 sebesar 72.7\% serta uji hipotesis KTSP dan Kurikulum 2013 kategori guru menunjukkan nilai $t_{\text {hitung }} 2.930$ dan $t_{\text {tabel }} 2.201$ yang artinya nilai $t_{\text {hitung }}$ lebih besar dari $t_{\text {tabel }}$ dengan nilai sig 2 tailled $0,008<0,05$. Dengan demikian maka pembelajaran PPKn dengan menggunakan kurikulum 2013 lebih efektif dari KTSP.

\section{Referensi}

\section{Sumber Jurnal}

Albantani, A. M. (2015). Implementasi Kurikulum 2013 Pada Pembelajaran Bahasa Arab Di Madrasah Ibtidaiyah. Jurnal Pendidikan Bahasa Arab dan Kebahasaaraban, 178-191.

Badriyah. (2015). Efektivitas Proses Pembelajaran Dengan Pemanfaatan. Lentera Komunikasi , 24422991.

Dewi, \& Setyo, Y. A. (2014). Analisis Implementasi Kurikulum Tingkat Satuan Pendidikan di Sekolah Dasar Negeri Pisang Candi 1 Malang.

Hakim, D. (2017). Penerapan Kurikulum Tingkat Satuan Pendidikan (KTSP) berkarakter dan Pengembangan Pendidikan karakter dalam meningkatkan Prestasi Belajar siswa di MAN 7 Jombang. Jurnal Managemen dan Pendidikan Islam, Volume 02 , 175 - 191.

Hakim, L. (2017). Analisis Perbedaan Antara Kurikulum KTSP dan Kurikulum 2013. Jurnal Ilmiah DIDAKTIKA , 280-292.

Hidayati, T. R. (2015). Implementasi Pengembangan Kurikulum 2013 Dalam Pembelajaran Pendidikan Agama Islam dan Budi Pekerti di SMA NEGERI 4 JEMBER. Fenomena .

Mukroni, S. (2017). Pengaruh Kualitas Pembelajaran Guru Ekonomi Terhadap Kepuasan Siswa di SMA Negeri 2 Sentajo Raya. Jurnal Pekbis , 140-150.

Post, D., \& Meng, Y. (2018). Does schooling foster environmental values and action Across-national study of prioritas and behaviors. International Jurnal of Education Development , 10-18.

Rosmani, A. H. (2017). Analisis Perbandingan Hasil Belajar Kimia Siswa Terhadap Penerapan KTSP dan Kurikulum 2013 di Beberapa Sekolah Favorit Banda Aceh . Jurnal Pendidikan Sains Indonesia , 94-101. 
Jurnal Inspirasi Pendidikan, VOL.9, NO.1, Edisi Januari 2019 Perbandingan Pembelajaran PPKn Pada Implementasi KTSP dan Kurikulum 2013 di SMP Bhakti Prima Findiga Hermuttaqien ${ }^{\text {a, }{ }^{*} \text {, Haula Ria Sata }}{ }^{\text {b, } 2}$, Ludovikus Bomans Wadu ${ }^{\text {c, } 3}$ Hal: $39-44$

Uce, L. (2016). Realitas Aktual Praktis Kurikulum : Analisis terhadap KBK, KTSP dan Kurikulum 2013. Jurnal Ilmiah DIDAKTIKA , 216-229.

\section{Sumber Buku}

Darmadi. (2017). Pengembangan Model Metode Pembelajaran Dalam Dinamika Belajar Siswa. Yogyakarta: CV Budi Utama.

Marwiyah. (2018). Perencanaan Pembelajaran Kontemporer Berbasis Penerapan Kurikulum 2013. Yogyakarta: CV Budi Utama.

Mulyasa, E. (2016). Pengembangan dan Implementasi Kurikulum 2013. Bandung: PT Remaja Rosdakarya Offset.

Sagala, S. (2013). Etika dan Moralitas Pendidikan Peluang dan Tantangan. Jakarta: Kharisma Putra Utama.

Sanjaya, W. (2008). Kurikulum dan Pembelajaran; Teori dan Praktik Pengembangan Kurikulum Tingkat Satuan Pendidikan . Jakarta: Prenadamedia Group.

Satriya, B. (2015). Paradigma Baru Pendidikan Kewarganegaraan Di Perguruan Tinggi. Tangerang Selatan: Nirmana Media.

Taniredja, T. (2009). Pendidikan Kewarganegaraan di Perguruan Tinggi Muhammadiyah. Bandung: Alfabeta, CV .

\section{Sumber Undang-Undang}

Depdiknas. (2003).Undang-undang Republik Indonesia Nomor 20 Tahun 2003 Tentang Sistem Pendidikan Nasional. Jakarta : Biro Hukum dan Organisasi Sekretariat Jendral Departemen Pendidikan Nasional. 